\title{
АНАЛИЗ ТРЕНДОВ РАЗВИТИЯ МИРОВОЙ АТОМНОЙ ЭНЕРГЕТИКИ
}

\author{
(c) 2018 Ханалиева Женнет Висампашаевна \\ аспирантка кафедры «Мировая экономика» \\ Российский экономический университет имени Г.В. Плеханова \\ E-mail: gennet91@gmail.com
}

Статья содержит исследование трендов развития атомной электроэнергии до 2050 года. Исследование проводилось на уровне всех 8 регионов мира, включающих в себя: Северную Америку, Латинскую Америку, Западную Европу, Восточную Европу, Африку, Ближний Восток и Южную Азию, Юго-Восточную Азию и Тихий Океан, а также Дальний Восток. Исследование трендов развития проводилось по абсолютным показателям энергетики (общая мощность и общий объем производства энергии, равно как всеми электростанциями, так и атомными), а также относительным показателям (\% долям ядерной энергии среди других ее видов, а также доли электроэнергии в расчете на одного человека данного региона мира). В качестве источника информации для изучения трендов развития применялись оценки тенденций в области энергетики, электричества и ядерной энергетики вплоть до 2050 года с использованием различных источников, таких как Информационная система энергетического реактора МАГАТЭ и данные, подготовленные Организацией Объединенных Наций.

Анализ изменения поведения одномерных и многомерных трендов развития мировой энергетики за период 2014-2050 годов по регионам мира проводился в разрезе трех показателей: потребление энергии на чел. (GJ/cap); потребление электроэнергии на чел. (MW.h/cap); потребление атомной электроэнергии на чел. (MW.h/cap).

Ключевые слова: атомная энергетика, мощность атомных электростанций, производство атомной электроэнергии, трендовый анализ, кластерная статистика, тренды формирования энергетики.

Трендовый анализ регионов-производителей атомной электроэнергии автором проводился на базе анализа трендов развития по совокупности показателей. Для анализа производимой атомной электроэнергии и ее процентной доли в совокупном объеме электроэнергии в период до 2050 года проведен анализ временного графика на рисунках 1 и 2.

Как следует из временных графиков на ри-

сунке 1, максимальные темпы роста производства атомной электроэнергии будут иметь государства Дальнего Востока и Восточной Европы. Более слабыми темпами будет расти производство в Северной Америке, на Ближнем Востоке и Южной Азии, Латинской Америке, а также Африке. Государства Юго-Восточной Азии и Океании согласно прогнозам станут производить атомную электроэнергию только к 2050 году, выйдя

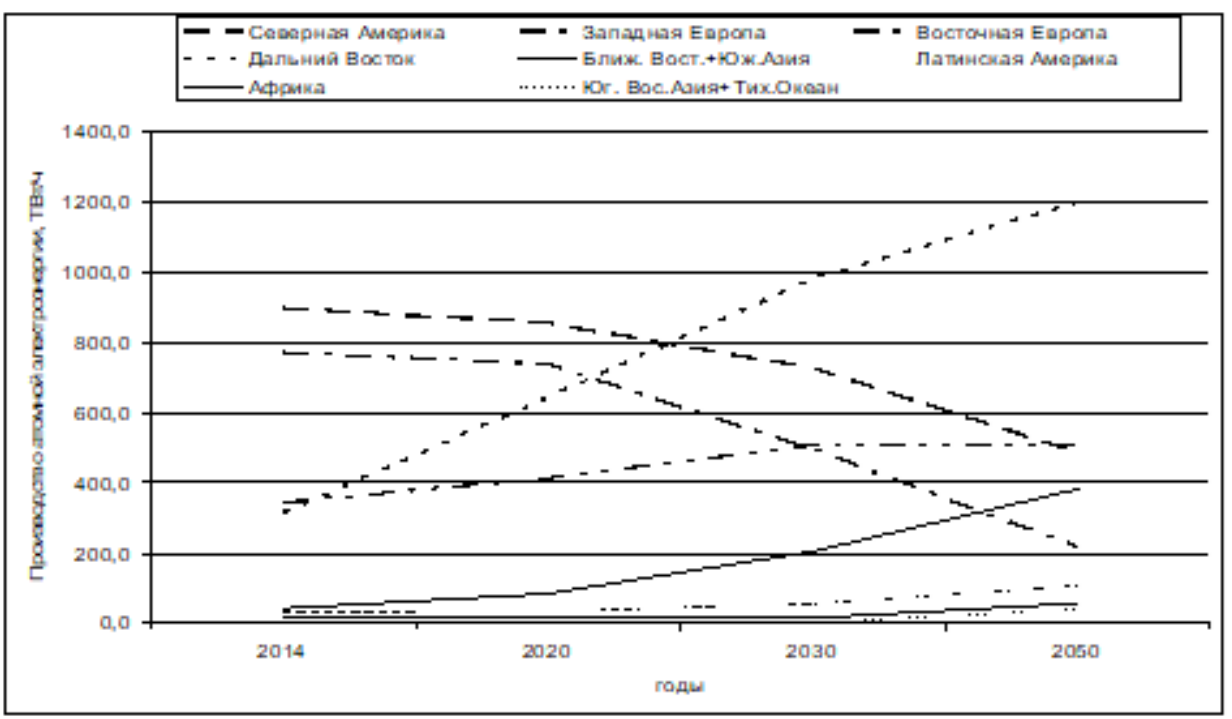

Puc. 1. Динамика роста производства атомной электроэнергии (ТВт/ч) Источник. Составлено автором по данным МАГАТЭ. 


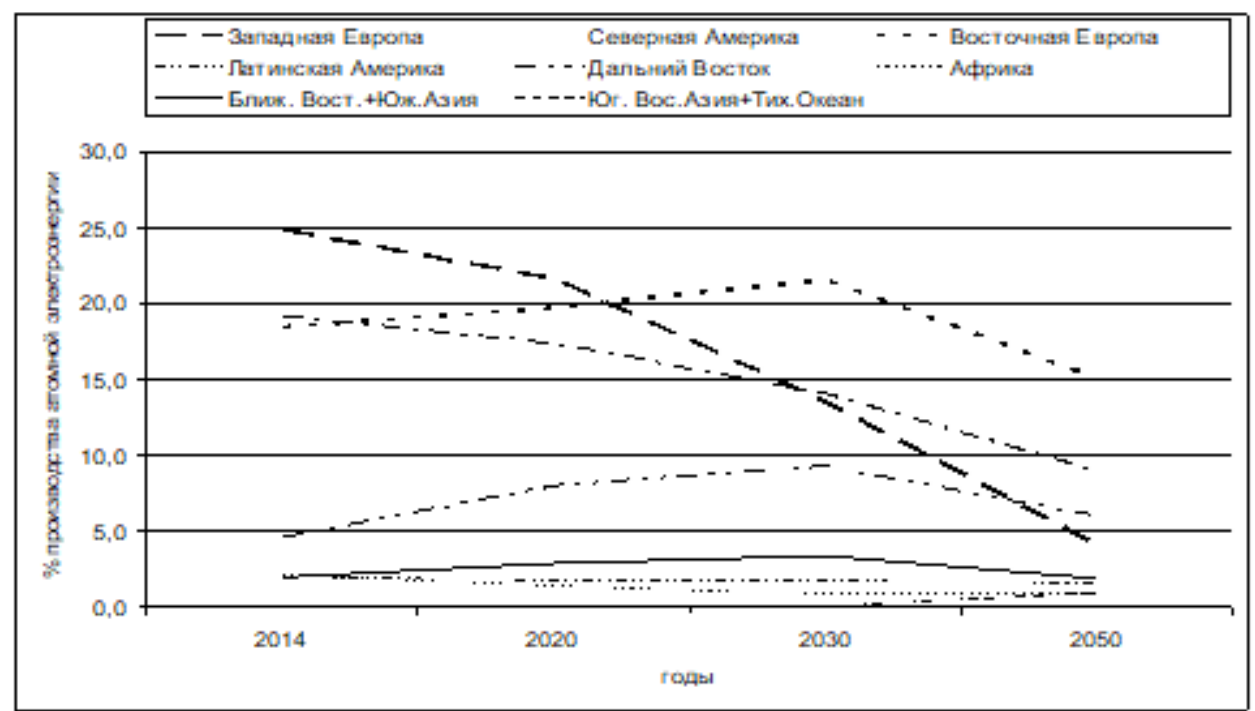

Puc. 2. Динамика доли (\%) производства атомной электроэнергии Источник. Составлено автором по данным МАГАТЭ.

на уровень 40,0 ТВт/ч. Что касается государств Западной Европы и Северной Америки, то они, напротив, намереваются сокращать атомную электроэнергию (Северная Америка в два раза, а Западная Европа - еще более существенно).

Тенденции к повышению доли атомной электроэнергии в совокупном объеме электроэнергии прослеживаются у государств Восточной Европы, Дальнего Востока, а также Ближнего Востока и Южной Азии. Вместе с тем, государства Западной Европы и Северной Америки намереваются уменьшать долю производства атомной электроэнергии. Другие регионы мира также намереваются незначительно снизить долю производства атомной электроэнергии.

Для исследования многомерных трендов развития с использованием временных рядов каждый регион мира представлен шестью показателями мощности и производства: общая мощность, ГВт; атомная мощность, ГВт;\% атомной мощности; общее производство электроэнергии, ТВт/ч; производство атомной электроэнергии, ТВт/ч;\% производства атомной электроэнергии. Каждый из данных показателей был представлен четырьмя временными данными: за 2014, 2020, 2030 и 2050 годы.

В итоге работы алгоритма построения топологической карты автором был создан набор топологических карт, на котором сформировалось 6 кластеров C1-С6, которые отмечены на рисунке 3. На карту нанесены названия состояний, представленных парой «год-регион».

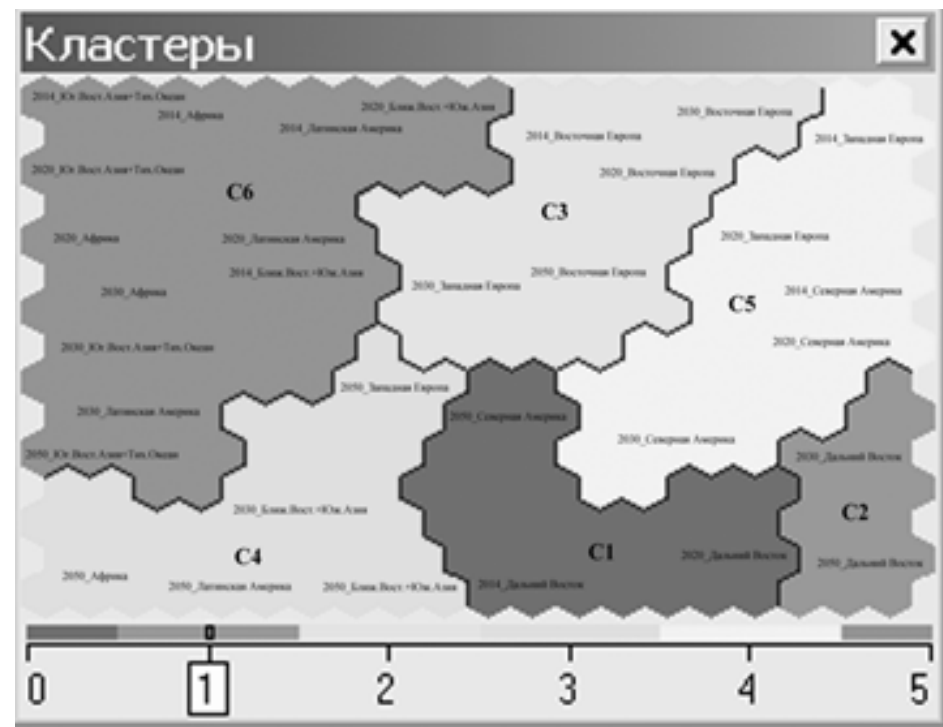

Puc. 3. Карта кластеров для регионов-производителей в 2014-2050 гг.

Источник. Составлено автором 
Кластер C1 расположен в зоне средних значений показателей мощности и производства общей генерации и атомной энергии и средних значений производства атомной энергии и\% производства атомной электроэнергии.

Кластер С2 является лидером и расположен в зоне высоких значений почти всех показателей (мощность и производство общей генерации и атомной энергии), кроме показателей\% доли производства атомной энергии и\% атомной мощности, которые находятся в зоне средних значений.

Кластер C3 расположен в зоне низких значений показателей мощности и производства общей генерации, средних значений атомной мощности и производства атомной электроэнергии и высоких значений показателей\% атомной мощности и\% производства атомной энергии.

Кластер C4 расположен в зоне высоких значений показателей мощности и производства общей генерации. По всем остальным показателям кластер находится в зоне низких показате- лей.

Кластер C5 расположен в зоне высоких значений долей генерируемых атомных мощности и энергии, низких значений общей мощности и средних значений общего производства электроэнергии.

Кластер С6 является аутсайдером и расположен в зоне низких значений всех показателей.

Результаты кластерной статистики, отображающие средние по кластерам значения показателей приведены в табл. 1.

Для того, чтобы осуществить анализ многомерных трендов на карту кластеров нанесли траектории формирования регионов мира за период 2014-2050 годов, соединив соответствующие метки линиями (рисунок 4).

Северная Америка, перемещаясь по карте из кластера С5 в кластер С1, существенно меняет и свою позицию, переходя из зоны средних в зону высоких значений мощности и производства всех видов энергии, и одновременно сокращая соответствующие доли атомной энергии.

Дальний Восток улучшает свои показатели,

Таблица 1. Кластерная статистика, средние показатели по кластерам

\begin{tabular}{|l|c|c|c|c|c|c|}
\hline \multicolumn{1}{|c|}{ Показатель/кластер } & $\mathbf{C 1}$ & $\mathbf{C 2}$ & $\mathbf{C 3}$ & $\mathbf{C 4}$ & $\mathbf{C 5}$ & $\mathbf{C 6}$ \\
\hline Общая мощность, ГВт & 1906,0 & 4075,5 & 801,4 & 2642,0 & 1202,0 & 548,8 \\
\hline Атомная мощность, ГВт & 81,9 & 140,4 & 58,9 & 24,2 & 105,0 & 3,8 \\
\hline \% атомной мощности & 4,3 & 3,7 & 7,9 & 0,9 & 8,9 & 0,7 \\
\hline Общее производство электроэнергии, ТВт/ч & 6766,3 & 15220,0 & 2670,6 & 8957,2 & 4244,4 & 1948,3 \\
\hline Производство атомной электроэнергии, ТВт/ч & 479,9 & 1090,0 & 453,0 & 192,8 & 796,8 & 27,2 \\
\hline \% производства атомной электроэнергии & 7,2 & 7,7 & 17,6 & 2,4 & 19,4 & 1,3 \\
\hline
\end{tabular}

Источник. Составлено автором.

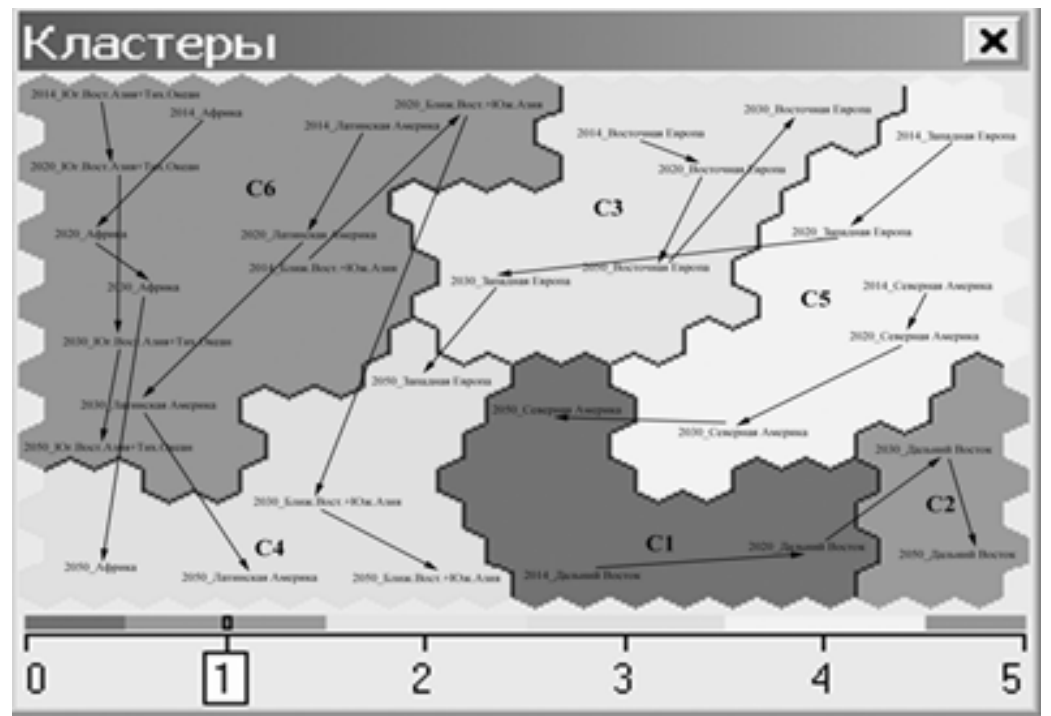

Puc. 4. Многомерные тренды регионов мира за период 2014-2050 гг. Источник. Составлено автором 
перемещаясь по карте вправо из кластера С1 в кластер С2, лидирующий по всем показателям. Западная Европа также существенно сокращает эти доли, переходя из кластера С5 в кластер С4 с низкими значениями показателей атомной мощности и производства атомной электроэнергии, а также\% долей мощности и производства атомной энергии. Страны Восточной Европы, хоть и оставаясь в пределах кластера С3, переместились в зону высоких значений долей мощности и производства атомной энергии. Остальные регионы, постепенно смещаются в рамках кластера С6 вниз и вправо по карте к границам кластеров С3 и С4, стремясь улучшить свои показатели.

Все регионы, за исключением Западной Европы, стараются повысить показатели потенциала атомной электроэнергии, причем Северная Америка осуществляет это не так интенсивно, как следовало ожидать. Как заметно из описаний по картам многомерных трендов, регионы Латинской Америки, Африки, Ближнего Востока и Южной Азии, а также Юго-Восточной Азии и Тихого Океана имеют идентичные по ориенти- рованности траектории формирования атомной электроэнергии.

Таким образом, концентрация производства атомной энергии в период до 2050 года по регионам мира станет постепенно падать. Относительное выравнивание ожидается за счет снижения к 2050 году производства атомной энергии Западной Европой и существенным увеличением атомной электроэнергии в государствах Дальнего Востока и Восточной Европы.

Анализ динамик прогнозов мощности и производства атомной энергии до 2050 года демонстрирует растущие тренды для государств Дальнего Востока и Восточной Европы. Более плавными темпами станет увеличиваться производство в Северной Америке, на Ближнем Востоке и Южной Азии, Латинской Америке и Африке. У Западной Европы, напротив, в намерениях постепенное снижение атомной электроэнергии и переключение на альтернативные источники энергии. Стоит отметить, что, невзирая на рост объемов атомной электроэнергии в государствах Северной Америки, ее доля в совокупном объеме электроэнергии снижается.

\section{Библиографический список:}

1. МАГАТЭ. Оценки энергии, электроэнергии и ядерной энергии на период до 2050 года. Вена, 2015.

2. Прогноз развития энергетики мира и России до 2040 года / ИНЭИ РАН // [Электронный ресурс].- Режим доступа: https://www.eriras.ru/files/prognoz-2040.pdf

3. Тренды и сценарии развития мировой энергетики в первой половине XXI века / А. М. Белогорьев, В.В. Бушуев, А.И. Громов, Н.К. Куричев, А.М. Мастепанов, А.А. Троицкий.- М.: Институт энергетической стратегиИ, ИД «ЭНЕРГИЯ», 2011.- 68 с.

4. Черкасенко А.И. Тенденции развития мировой атомной энергетики // Проблемы современной экономики. 2006. № 1 (17). 0,4 п.л.

5. Черкасенко А.И. Мировой рынок ядерного топлива и ядерного энергетического оборудования: вопросы участия России // Экономика ХХІ века. - 2008. - № 10.- С. 3-9.

6. Ядерные силовые реакторы в мире. 2016. Международное атомное энергетическое агентство. Вена, 2017. http://www-pub.iaea.org/books

7. Отчет Агентства по ядерной энергии http://www.nea.fr

8. Доклад американского ядерного общества http://www.ans.org

9. Отчет Всемирной ядерной ассоциации http://www.world-nuclear.org

10. Отчет Института ядерной энергии http://www.nei.org

11. Доклад Комиссии по ядерному регулированию США (NRC) http://www.nrc.gov

12. Мировая энергетическая статистика. Ежегодник 2016. Режим доступа: https://yearbook.enerdata.ru/\#СO2emissions-data-from-fuel-combustion.html

13. Официальный сайт ГК «Росатом» http://rosatom.ru/

14. Соболь М. С., Быкова А.В. Конкурентоспособность России на мировом рынке атомной энергетики // Молодой ученый. 2017. № 2. С. 508-511.

15. Эволюция мировых энергетических рынков и ее последствия для России / под ред. А.А. Макарова, Л. М. Григорьева, Т.А. Митровой// ИНЭИ РАН-АЦ при Правительстве РФ. Москва. 2015. 400 с.

16. Энергетическая стратегия России на период до 2020 г. // [Электронный ресурс].- Режим доступа: http:// www.minprom.gov.ru/docs/strateg/ 
17. Статистический обзор ВР Мировой Энергии [Электронный ресурс] // ВР. - 2016. - 65-е издание.- Режим доступа: http:/www.bp.com/content/dam/bp/pdf/energy-economics/statistical-review-2016/bp-statisticalreview-of-world-energy-2016-full-report.pdf

18. Bloomberg New Energy Finance: Renewable Energy [Electronic resource] // Bloomberg. - 2015. - Mode of access: http://about.bnef.com/content/uploads/sites/4/2015/10/2015-10-08-Clean-Energy-Investment-2015-factpack. pdf

19. Global Wind Statistics 2015 [Electronic resource] // Global Wind Energy Council._-2016. - Mode of access: http:// www.gwec.net/wp-content/uploads/vip/GWEC-PRstats-2015_LR_corrected.pdf

20. IAEA PRIS Power Reactor Information System. https://www.iaea.org/PRIS/WorldStatistics/ OperationalReactorsByCountry.aspx 